\title{
Pivotal Points in Utilizing Cloud Services in Turkey
}

\author{
Asst. Prof. Dr. Ediz Şaykol (Beykent University, Turkey) \\ Ayşe Seçil Avcı (Nişantaşı University, Turkey)
}

\begin{abstract}
The term of Cloud Computing has become a buzzword that almost every single person has heard. Although, it is defined at various platforms in various ways even with exactly different sentences, the most wide-reaching definition was made by NIST as a model for enabling convenient, on-demand network access to a shared pool of configurable computing resources with minimal management effort or service provider interaction. As Cloud Services entered daily lives, organizations and even ordinary people started to manage their business at any time anyplace in solid and reasonable costs with the help of considerably faster, at a high performance level, flexible clouds. The datas, softwares and platforms that stored in cloud has become accessible from where you are without a need of a server center. These lead to the problem of selecting and providing appropriate cloud services for customers and providers, respectively. The relation between these two depends on a win-win relationship, and hence the pivotal points that they raise becomes crucial from business perspective. In this study we present an analysis for the IT sector in Turkey to elaborate on a possible set of pivotal points from Cloud Customer and Cloud Service Provider perspectives depending on a survey-based study.
\end{abstract}

\section{Introduction}

Cloud Computing has become a buzzword that almost every single person has heard. It has been defined at various platforms in various ways even with exactly different sentences; however, the most widespread definition was made by United States National Institute of Standards and Technology (NIST). As NIST defines, "Cloud Computing is a model for enabling convenient, on-demand network access to a shared pool of configurable computing resources (e.g., networks, servers, storage, applications, and services) that can be rapidly provisioned and released with minimal management effort or service provider interaction" (NIST, 2014). Besides many utilities it provides, the fact that it helps out companies to reduce costs outshines all the others.

Whereas considering the datas and even some basic documents- those needed to be stored in computer-which a random person can have in his entire life it is predictable that a huge storage area is needed. Moreover, the need of being provided software, infrastructure, and platforms as a service is much bigger amongst companies. In older times, industries built up their own server\&data centers. These server centers have been an impediment for companies since because they were conceiving extra expenses and waste of time. On the other hand, lack of flexibility and not being at a desired performance level were handicaps for companies (Armbrust et al., 2009).

There has become such no more need for these server centers after Cloud Computing entered daily lives. Instead, organizations, companies or even ordinary people started to manage their business at any time anyplace in solid and reasonable costs with the help of considerably faster, at a high performance level, flexible clouds. The datas, softwares and platforms that stored in cloud has become accessible from where you are without a need of a server center. Deciding to move an existing service to the cloud depends various factors both economical and technological, such as the expected resource utilization, and various operational costs depending on the cloud environment being considered, as discussed deeply in (Saykol, 2014).

In the Cloud Computing story there are two leading roles: Cloud Customer and Cloud Service Provider. This connection between them depends on a win-win relationship. The key point advantage that it brings makes Cloud Computing preferable as well as the utilities that customers can have in a wide variety. From computer engineering point of view, there is also another role, namely Cloud Service Developers, however the details of this role is outside the scope of this paper (McCabe and Nachbar, 2010).

In this paper, some preliminary information is given in Section 2 for those who are unfamiliar to cloud computing terms at all. Section 3 and Section 4 are discussing the main purpose of the paper which is to let you take a look at to key points of Cloud Computing from both cloud Service Provider's and Cloud Customer's perspective in Turkey. Finally, Section 5 concludes the paper.

\section{Preliminaries on Cloud Computing}

Essentially, cloud computing is not a technology that has just entered into our lives. More than 10 years we have been using services such like Msn, Hotmail, etc. In fact, the main reason that made it this much developed and spreaded is the development of bandwidth technologies. Workload of the firms is already not just staying at work. Workers may need to reach their files from anywhere any second. In the circumstances you need to work at home, you have to be at office since because the files and folders are there. But if we take a look at Cloud Computing; the place where you are is not important, you are not connected to office, you can work from where 
ever you are. Not you, the files are going to work depending on you and you can see the benefits of this technology that yield to your company.

Cloud computing lets datas heap together in one center and widen work place area. It takes away the complexity of infrastructure. Decidedly, it reduces the cost. Cloud Computing is the technology that lets you reach the data in the fastest way it can without a setup need and with a low cost. Figure 1 provides an overview on cloud computing notion.

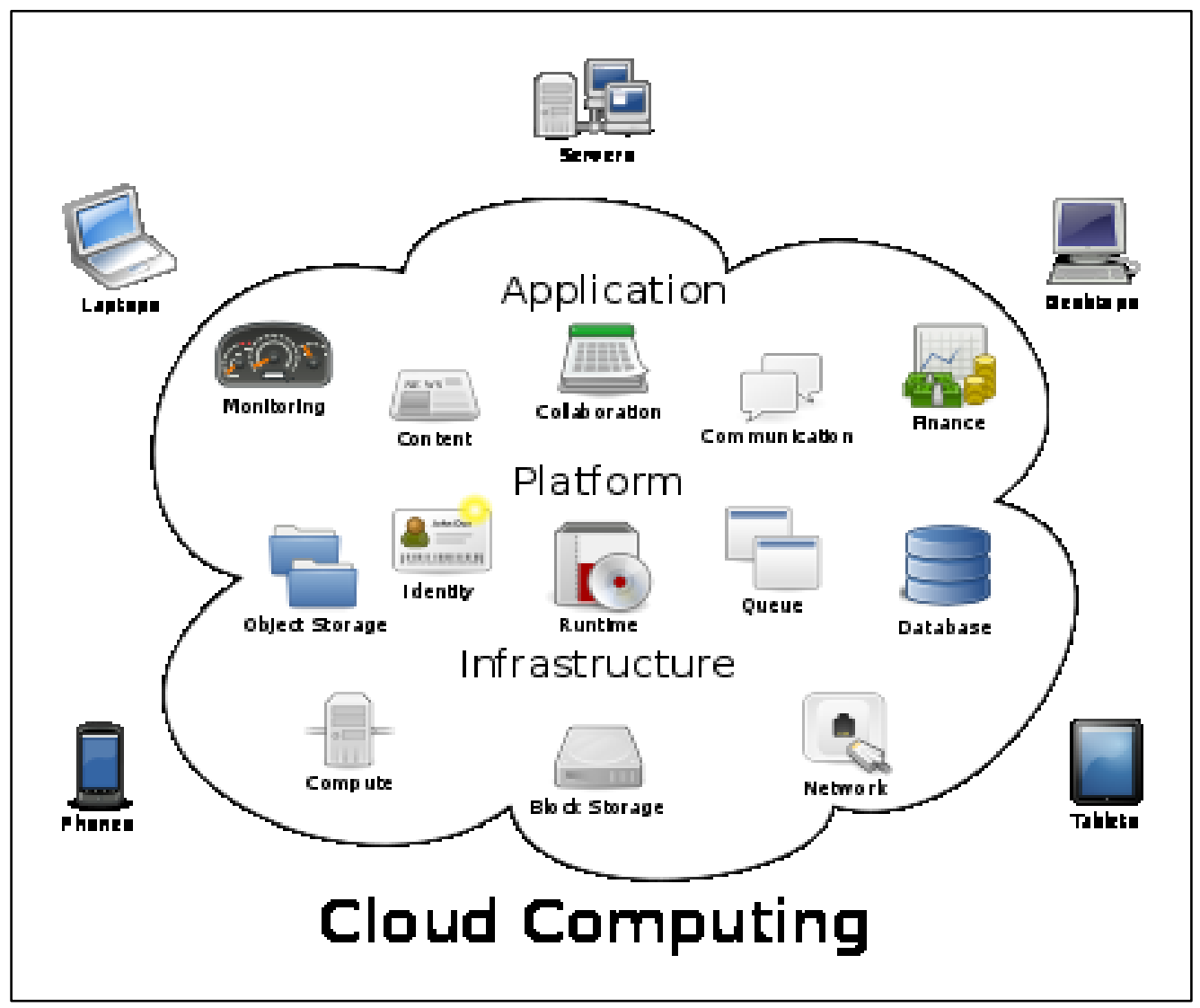

Figure 1. Cloud Computing overview. Source: (Infraworx, 2015)

Cloud Computing Service Models

A definition that is made in a shorten and coherent way about cloud computing would be that it is the remote control of the necessaries such like hard disk, software, hardware etc. Likewise, it helps getting access to pictures, documents, music and video files via other computers. In this manner, cloud computing is that using the necessary domain in every place that has internet connection and in an efficient way.

Cloud technology -in simplest- is the software applications that is accessible through internet, data storage services and operation capacity. In this technology, accessing to the informatique facilities that companies need at any time (or whenever it is needed) anyplace is grounded on (Papazoglou et al., 2007).

Cloud computing gives us solutions with 3 different service supplier models:

- Software as a Service (SaaS): Software service, yields programs such like CRM, ERP, Finance and Accounting software via Cloud. For the companies which have different office locations, SaaS doesn't have extra software costs and by this way SaaS provides a serious economic advantage.

- Platform as a Service (PaaS): Platform service, yields hardware and software layers to application developers to let them develop their projects. This service offers platforms such like system management, operating system, programming languages platform, database etc. Since the system management is carried out by service supplier, you only manage your applications and datas.

- Infrastructure as a Service (IaaS): Infrastructure service lets you take advantage of software, dataware house or network devices without any investing in and with fully help of an external source. 


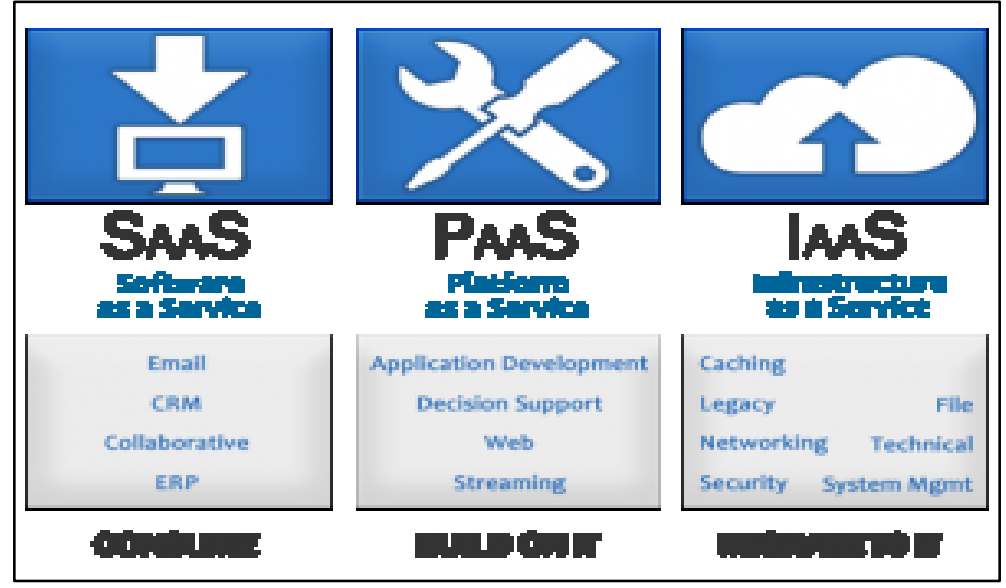

Figure 2. Cloud computing service models. Source: (Consultia, 2015)

As shown in Figure 2, these services determine the service level that we get and designate the ways for businesses to adopt cloud computing to their services. As a consumers, businesses generally find SaaS adequate, however, if the companies would like to develop services they prefer PaaS. Even further, business organize specialized teams and utilize cloud services as IaaS.

\section{Adopting to Business Models}

Just like the rest of the World, from every sector different sizes of corporations are using the cloud information services in Turkey as well. According to researches the number of the users who are using cloud services are same as the ones in Eastern Europe and Middle East, yet the number is still lower than the users in Western Europe and America. But the need and demand is rapidly increasing. There are quiet many local firms in Turkey who are in service for the cloud services (Y1ld1z, 2009).

Software application developers, small businesses and the students are using cloud services which do not have serious access and service agreements but simply agreeing a common terms and conditions text and they even can purchase these services with their credit cards. However middle sized businesses and corporate firms are preferring well written agreements for their special needs and respecting the data pricay for longer terms.

The service that is provided in Turkey is actually an all virtual data center. The firms can simply use a browser to access the cloud for doing anything that they can do on their local data center. This means that you do not need the space and the infrastructure like air-conditioning systems, ups, generators and the security for a data center anymore. Continuous and backup connection services are provided with this service as well.

One can create all of the servers, design the system, manage the firewall and make load balancing definitions virtually over the cloud. One can increase or decrease the sources on demand. Over all one can do all of these from a single screen and can see the real time cost of the services. One can even add different devices to cloud and manage them all from the same screen.

Figure 3 graphically list the top ways businesses adopt clod computing to their businesses. The results are based on a survey report, and provided in Forbes magazine. Not surprisingly, most businesses require cloud computing to reduce their cost, and provide efficient workforce, possibly via mobile devices. The businesses also assume that the time-to-market duration would be faster with the help of cloud computing.

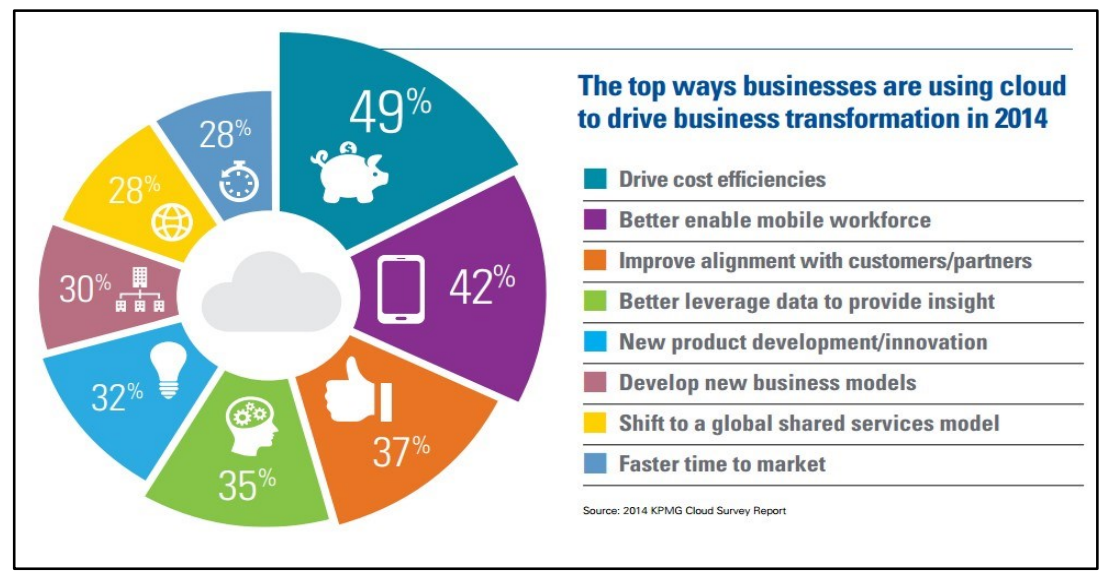

Figure 3. The top ways that businesses utilize cloud computing to your service. Source: (Forbes, 2015) Key Points in Selecting Cloud Computing 


\section{From Service Provider Point of View}

The budget for the infrastructures and technologies for the traditional IT models has its own problems like instead of monthly, annually or per user fees; firms has to deal with new technology or infrastructure costs. No such fees are needed for the use of cloud services. Instead of that you just have to pay for the apps per user every month which you can exclude from operational budgets.

Low cost and small budgets are the main reason for the demand on cloud services. The on-demand softwares are billed by per user and per use principles so the service cost becomes much cheaper than the on premise softwares. Besides that SaaS softwares does not need extra hardware or extra human resources. The classical licensed softwares updates are done annually with a need for an update fee where the SaaS softwares are always up to date and these updates are free of charge.

Worldwide access is another reason for the popularity of the use of the cloud services. Users can access the services from anywhere on the world from any computer without the need for an office or installation of a software. Lately, this need has shifted from the business use to personal use as well. Besides that the specification of the computer for using these services are not necessarily needs to be high end. A middle level simple computer can be adequate for these services.

These are numerous improvements for the cloud services on access levels. One of them is the minimization of the business risk factors. The Service providers' enormous data farms have a lot of infrastructures for the security of the data. Also the numerous numbers of the backups allows additional security in case of the data loss.

But when it comes to the use of the cloud services, besides the benefits of the higher mobility the constant access to the cloud has to be kept in mind. Mobile users can use the services outside the office constantly. The full integration of the windows phone for the cloud services makes the use of these services more effective.

Some other advantages for the use of this technology are: The compatibility between different operating systems, the openness for the group work, privacy, security, unlimited storage, etc. The SaaS softwares are generally provided with free test times. This allows the users to assess the benefits and comfort that the software provides for them.

\section{From Service Provider Point of View}

It is for sure that we must be careful and reasonable while taking advantages of cloud computing benefits. The most important issue that it has to be taken serious is security. There are 3 matters that you must be careful on:

- Work persistence

- Service persistence (that you get from supplier)

- Security of your datas

For the first two cases, the solution might be to work with a service supplier that improved it and has strong references. Means, you need to investigate the firm that you get cloud services from about how much capital it invest in and how dependable it is. You can decide from checking firm's background if it is a vision holder company or not.

From a cloud service supplier's perspective; it is also more reasonable to work for cloud services. Any computer stays free for a $99.9 \%$ part of its processing time or keeps doing $1 / 0$. Since there is this much of a processing power, it is precisely logical to sell it/share it to/with some other people.

In older times, many majority of companies were spending almost $100.000 \$$ for computers or $50.000 \$$ for server centers, many thousand dollars for hardware, another thousand dollars for each computing brand, etc. While paying this much of money, people were being directed to oneself, each time to different people. In this circumstances, serious moneys were spent and serious invests were made. As the result of this vicious cycle, OPEX (operational expenditure) was increasing from day to day. Here, cloud service suppliers sell cloud solutions to decrease this expenditure.

What companies do is to buy hardware and hire it, maintain it, if it is necessary expand the capacity. Those can hire the same virtual machine to different companies at different time periods. As an example, assume one of those virtual machines is hired by 5 people. Simply, that single machine will fulfill its cost.

Just to give an example to this 'hire' issue, we can show SaaS (Software as a Service) solutions. Many software products developed by software developers might be so expensive. Hence, there are not that many of companies and people who can buy software that costs $100.000 \$$. It requires being at a highly financial power level to spend that money. There might be only a few people who can effort this but with cloud services this software can meet with millions of people. By this way, cloud supplier can get a chance to service to wide range of communities. This is another reason to be a cloud service supplier; being preferable by millions. The main reason and gain of cloud service provider is to reduce total cost of ownership.

Many companies that serve cloud service solutions in Turkey give IaaS (Infrastructure as a Service) solutions to customers. That is to say, those build up a full automatic system by virtualizing hosts and give various 
solutions with 3rd party solution partners. Such system examples can be given among the uses in accounting systems (Seyrek, 2011).

\section{Evaluating the Situation in Turkey}

In this study it is intended to highlight the key point benefits of both when buying and selling cloud computing services. It is for sure that cloud computing brings many eases to daily and professional lives. There are even several more reasons to get it or provide it. The most common and guarantee reason to get is money austerities. The smart face of cloud computing's on-demand services brings many utilities on economical side.

The adaptation of cloud services and cloud usage status in Turkey is discussed in (Saykol, 2014). Moreover, in a joint work supported by TÜBITAK, the companies in Turkey are interested in the new technological trends, such as Cloud Computing (Silahtaroğlu et al., 2014).

The following are the key points that were determined as important by the companies, actually cloud service users, in Turkey.

- Dependency to the cloud service provider: This dependence reduces the freedom of the company to work with other solution providers, and other $3^{\text {rd }}$ party companies (Armbrust et al., 2009). Hence, the companies pay importance to this item.

- The capacity of the network bandwidth: The amount of cloud use necessitates high bandwidth for the companies (Saykol, 2014). If the size is not enough for the products/services of the company, this will lead to a business failure, which businesses surely do not accept.

- Network security, especially data confidentiality: The company-specific data and the customer data that the companies hide should not be accessed by other parties. Even though most cloud providers have enhanced security and confidentiality mechanisms (McCabe and Nachbar, 2010), the business are quite reluctant to use these cloud services.

- Compliancy with the standards and governmental regulations: Businesses generally prefer service-level agreements with the service providers, as other utility services, such as electricity. However, the companies would like their cloud to be adaptive and compliant with the governmental regulations (Yildiz, 2009). In Turkey, the laws and regulations change quite frequently depending on the technological needs and to care data privacy, the business do not want to pay more attention to these issues by themselves. In fact, they require the cloud service provides take care of these.

\section{Conclusion}

As the widespread of Cloud Services in our lives, organizations and even ordinary people started to manage their business at any time anyplace in solid and reasonable costs with the help of considerably faster, at a high performance level, flexible clouds. The datas, softwares and platforms that stored in cloud has become accessible from where you are without a need of a server center. These lead to the problem of selecting and providing appropriate cloud services for customers and providers, respectively.

Here, we present an analysis for the IT sector in Turkey to elaborate on a possible set of pivotal points from Cloud Customer and Cloud Service Provider perspectives depending on a survey-based study. We found that the key points that were determined as important by the companies, actually cloud service users, are dependency to the cloud service provider, the capacity of the network bandwidth, network security, especially data confidentiality, compliancy with the standards and governmental regulations.

In our future work, we would like to provide multi-criteria selection mechanisms for selecting appropriate service provides for the IT companies in Turkey based on the achievements in this work.

\section{References}

- $\quad$ Armbrust, Michael, Fox, Armando, Griffith, Rean, Joseph, Anthony D., Katz, Randy H., Konwinski, Andrew, Lee, Gunho, Patterson, David A., Rabkin, Ariel, Stoica, Ion and Zaharia, Matei, 2009, “Above the Clouds: A Berkeley View of Cloud Computing", UCB/EECS-2009-28, http://www.eecs.berkeley.edu/Pubs/TechRpts/2009/EECS-2009-28.html.

- $\quad$ Bayrak, Ergin, Conley, John Patrick and Wilkie, Simon, 2011, "The Economics of Cloud Computing", No 1118, Vanderbilt Uni. Dept of Economics, http://EconPapers.repec.org/RePEc:van:wpaper:1118.

- Consultia, 2015, “Cloud computing service models", http://www.consultia.co/choosing-your-right-cloud/.

- Forbes, 2015, “The top ways that businesses utilize cloud computing”, http://www.forbes.com.

- Hancock, Ian and Hutlay, Nikki, 2012, "Modelling the Economic Impact of Cloud Computing", KPMG Report, http://www.kpmg.com/au/en/issuesandinsights/articlespublications/pages/modelling-economicimpact-cloud-computing.aspx. 
- Infraworx, 2015, “Cloud Computing”, http://www.infraworx.com.

- $\quad$ Marston, Sean, Li, Zhi, Bandyopadhyay, Subhajyoti, Zhang, Juheng, Ghalsasi, Anand, 2011, “Cloud computing - The business perspective”, Decision Support Systems, 51, 176-189.

- $\quad$ McCabe, Karen, Nachbar, Robert, 2010, "Survey by IEEE and Cloud Security Alliance Details Importance and Urgency of Cloud Computing Security Standards", https://cloudsecurityalliance.org/media/news/surveyby-ieee-and-cloud- security-alliance-details-importance-and-urgency-of-cloud-computing-securitystandards/.

- National Institute of Standards and Technology (NIST), 2014, "Definition of Cloud Computing", http://www.nist.gov/itl/cloud/index.cfm.

- Papazoglou, Michael. P., Traverso, Paolo, Dustdar, Schahram, Leymann, Frank, 2007, "Service-Oriented Computing: State of the Art and Research Challenges", IEEE Computer, 64-71.

- Saykol, Ediz, 2014, "On the Economical Impacts of Cloud Computing in Information Technology Industry", Proceedings of 5th International Conference on Eurasian Economies (EECON'14), Skopje, Macedonia.

- Seyrek, İbrahim Halil, 2011, “Bulut Bilişim: İşletmeler için Fırsatlar ve Zorluklar”, Gaziantep Üniversitesi Sosyal Bilimler Dergisi 10(2), 701-713.

- Silahtaroğlu, Gökhan, Saykol, Ediz, Doğan, İdil, Kocamaz, Ahmet, 2014, "On the Use of Analytics in Turkey: A Data Mining Study”, Proceedings of 1st International Conference on Recent Trends and Applications in Computer Science and Information Technology (RTA-CSIT'14), Tirana, Albany.

- Yıldız, Özcan Rıza, 2009, "Bilişim Dünyasının Yeni Modeli: Bulut Bilişim (Cloud Computing) ve Denetim”, Sayıştay Dergisi, 5-23. 